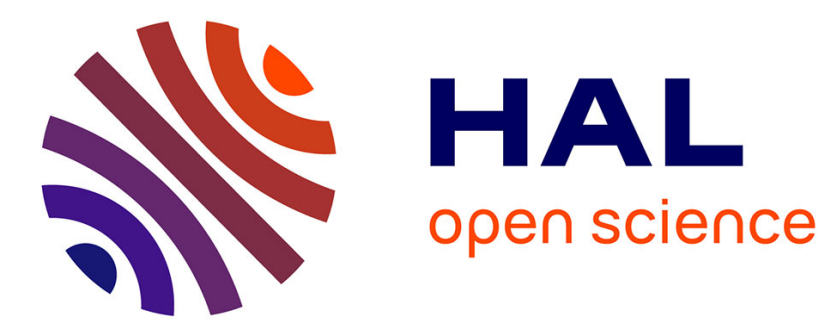

\title{
Pink Noise in Rowing Ergometer Performance and the Role of Skill Level
}

Ruud J.R. den Hartigh, Ralf F.A Cox, Christophe Gernigon, Nico W. van Yperen, Paul L.C. van Geert

\section{- To cite this version:}

Ruud J.R. den Hartigh, Ralf F.A Cox, Christophe Gernigon, Nico W. van Yperen, Paul L.C. van Geert. Pink Noise in Rowing Ergometer Performance and the Role of Skill Level. Motor Control, 2015, 19 (4), pp.355-369. 10.1123/mc.2014-0071 . hal-02519641

\section{HAL Id: hal-02519641 https://hal.science/hal-02519641}

Submitted on 26 Mar 2020

HAL is a multi-disciplinary open access archive for the deposit and dissemination of scientific research documents, whether they are published or not. The documents may come from teaching and research institutions in France or abroad, or from public or private research centers.
L'archive ouverte pluridisciplinaire HAL, est destinée au dépôt et à la diffusion de documents scientifiques de niveau recherche, publiés ou non, émanant des établissements d'enseignement et de recherche français ou étrangers, des laboratoires publics ou privés. 


\section{Pink Noise in Rowing Ergometer Performance and the Role of Skill Level}

Article in Motor control · October 2015

DOI: 10.1123/mc.2014-0071 · Source: PubMed

CITATIONS

17

5 authors, including:

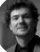

Ruud J.R. Den Hartigh

University of Groningen

45 PUBLICATIONS 312 CITATIONS

SEE PROFILE

Christophe Gernigon

Université de Montpellier

70 PUBLICATIONS 864 CITATIONS

SEE PROFILE

\section{READS}

898

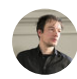

Ralf F A Cox

University of Groningen

92 PUBLICATIONS 906 CITATIONS

SEE PROFILE

Nico W. Van Yperen

University of Groningen

149 PUBLICATIONS 6,439 CITATIONS

SEE PROFILE

Some of the authors of this publication are also working on these related projects:

The effect of animal assisted interventions on the speech Language Development and social interaction of children with ASD and with Down syndrome View project

Dynamic Modeling of Action Planning View project 


\title{
Pink Noise in Rowing Ergometer Performance and the Role of Skill Level
}

\author{
Ruud J. R. Den Hartigh \\ University of Groningen
}

Ralf F. A. Cox

University of Groningen

Christophe Gernigon

University of Montpellier

\section{Nico W. Van Yperen and Paul L. C. Van Geert University of Groningen}

\begin{abstract}
The aim of this study was to examine (1) the temporal structures of variation in rowers' (natural) ergometer strokes to make inferences about the underlying motor organization, and (2) the relation between these temporal structures and skill level. Four high-skilled and five lower-skilled rowers completed 550 strokes on a rowing ergometer. Detrended Fluctuation Analysis was used to quantify the temporal structure of the intervals between force peaks. Results showed that the temporal structure differed from random, and revealed prominent patterns of pink noise for each rower. Furthermore, the high-skilled rowers demonstrated more pink noise than the lower-skilled rowers. The presence of pink noise suggests that rowing performance emerges from the coordination among interacting component processes across multiple time scales. The difference in noise pattern between high-skilled and lower-skilled athletes indicates that the complexity of athletes' motor organization is a potential key characteristic of elite performance.
\end{abstract}

Keywords: complex systems, detrended fluctuation analysis, elite performance, interaction dominance, motor control, temporal structures

Sport scientists have recently proposed that major advances can be made when considering sport and motor performance as emerging from complex systems

Den Hartigh, Cox, Van Yperen, and Van Geert are with the Dept. of Psychology, University of Groningen, Groningen, Netherlands. Gernigon is with the Dept. of Sport and Physical Education Sciences, University of Montpellier, Montpellier, France. Address author correspondence to Ruud J. R. Den Hartigh at j.r.den.hartigh@ rug.nl. 
interactions (Davids et al., 2014; Seifert, Button, \& Davids, 2013). In this sense, coordinated actions such as rowing strokes would emerge from continuous interactions between component processes at different levels and time scales (e.g., cell activity, muscle contractions, limb movements), embedded in (and shaped by the constraints of) the environment (Davids \& Araujo, 2010; Seifert et al., 2013). In the domain of motor control, researchers have demonstrated that the temporal structure of performance variation may provide fundamental insights into the nature and effectiveness of the dynamic organization underlying the performance (e.g., Glass, 2001; Goldberger et al., 2002). For instance, random variation in stride intervals signals a higher risk of falling among elderly, whereas "healthy" stride intervals involve an appropriate ratio between rigidity and random variation (e.g., Goldberger et al., 2002; Hausdorff et al., 1997, 2001). Researchers have suggested that the latter type of "noise" reveals the presence of complex network interactions across brain and body, which means that motor control is distributed over cooperative processes at different levels of the motor system (for a review, see Wijnants, 2014). Although the complex systems perspective is gaining popularity in sport sciences, and researchers assume that effective or skilled sport performance requires a form of functional variability to satisfy environmental constraints (i.e., between rigidity and random; see Davids, Glazier, Araújo, \& Bartlett, 2003; Phillips, Portus, Davids, \& Renshaw, 2012; Seifert et al., 2013), empirical studies focusing on noise patterns in sport performance are still relatively scarce.

The study of temporal structures of variation (i.e., noise patterns) and its meaning has a relatively long history in physical sciences (e.g., Bak, Tang, \& Wiesenfeld, 1987; Dutta \& Horn, 1981; Press, 1978), and has gained popularity in the domains of cognitive sciences and motor control in the past two decades (e.g., Gilden, Thornton, \& Mallon, 1995; Goldberger et al., 2002; Hausdorff et al., 2001; Van Orden, Holden, \& Turvey, 2003; Wijnants, 2014). Overall, three types of temporal structures can be distinguished, which lie on a continuum from white noise to brown noise (see Figure 1). White noise corresponds to purely random variation, and is assumed to be typical for component dominant systems (Van Orden et al., 2003). In the domain of motor control this would mean that the temporal variability in an action sequence is generated by random fluctuations in the component-processes (e.g., domain-specific control structures such as classical central pattern generators), resulting in an uncorrelated time series (Figure 1A; see also Diniz et al., 2011; Gilden, 2001; Van Orden et al., 2003; Wijnants, 2014). Brown noise corresponds to a stochastic function where each subsequent measure is relatively close to each preceding measure, which is assumed to be typical for systems composed of components that are tightly mutually connected. More specifically, each subsequent action is a function of the previous action to which a random increment is added, characteristic of a rigid pattern of behavior. Brown noise is reflected in time series by short-range correlations between sequential actions (Figure 1C; see also Gilden, 2001; Van Orden et al., 2003). In between white noise and brown noise lies pink noise, which expresses a subtle mixture of randomness and rigidity. Pink noise would be typical for interaction dominant (complex) systems (e.g., Glass, 2001; Van Orden et al., 2003; Wijnants, Bosman, Hasselman, Cox, \& Van Orden, 2009; Wijnants, 2014). Because of the mutual interactions between flexibly coupled system components 


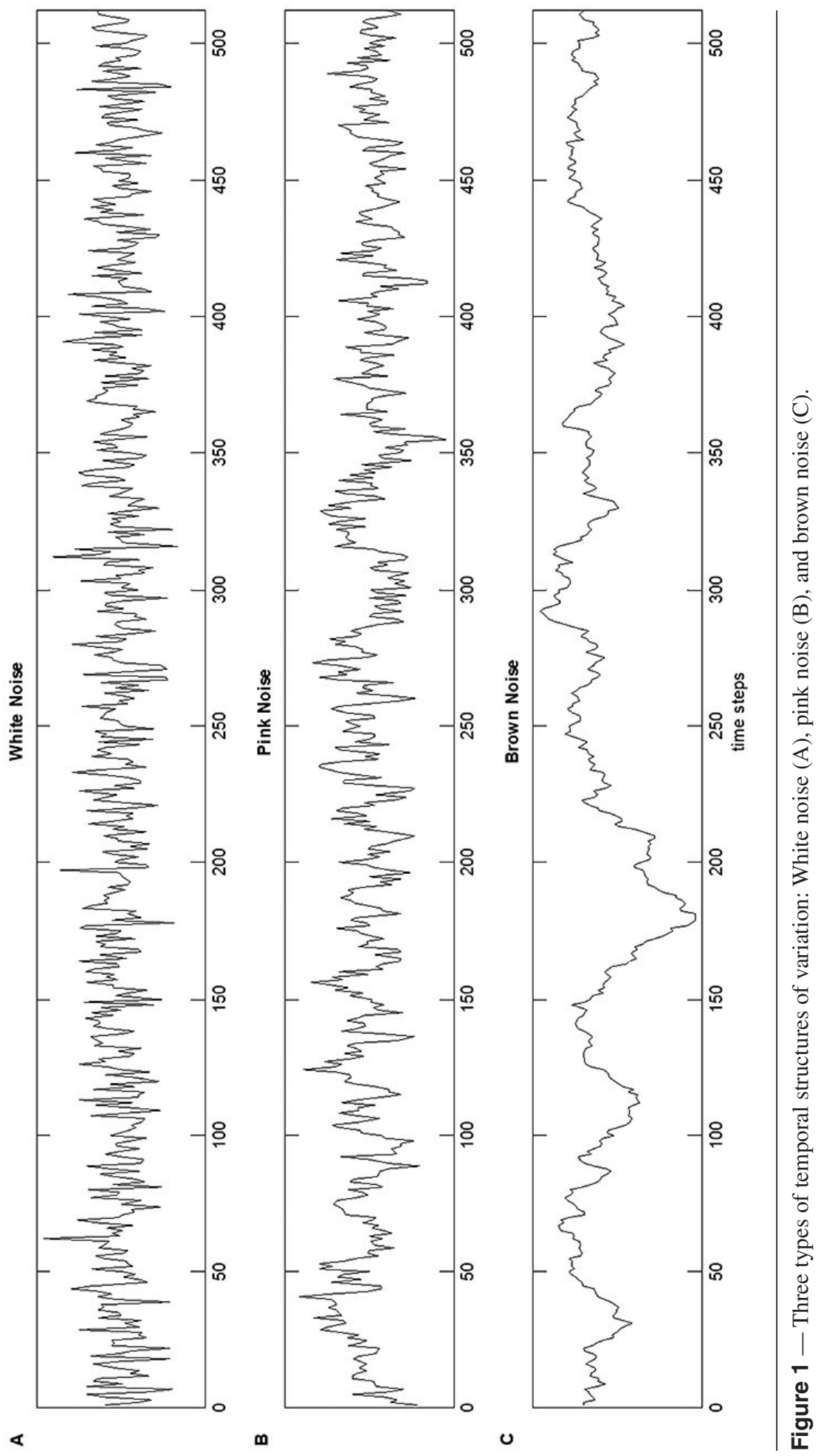


across multiple time scales, time series of interaction dominant systems behavior would display long-range dependencies between sequential actions (Figure 1B).

Although applications of nonlinear time-series techniques to reveal temporal structures of variation are in their infancy in sport sciences (Kuznetsov, Bonnette, \& Riley, 2014), deviations from white noise have already been found in running and cycling performance (Hoos, Boeselt, Steiner, Hottenrott, \& Beneke, 2014; Tucker et al., 2006). Hoos et al. (2014) studied fluctuations in speed, stride frequency, and stride length of long-distance runners during a half-marathon competition race, whereas Tucker et al. (2006) examined fluctuations of power output while cyclists were performing maximally during a time trial on cycle ergometers. To summarize, both studies reported nonrandom temporal patterns in performance variation (i.e., signatures of brown and pink noise).

However, Hoos et al. (2014) and Tucker et al. (2006) examined athletes' in competitive situations, which may have acted as an additional constraint on the control of the athletes' movements. Indeed, according to the authors, the noise patterns they found would be typical for athletes' pacing during a competition or time trial. This implies that the situations in which the participants performed probably affected the motor system by "pushing" it into a more rigid organization, thereby eliciting brown noise signatures. As indicated earlier, research outside sports has shown that time series of "natural"—and healthy-motor performance exhibit prominent patterns of pink noise, characterized by an optimal mixture of randomness (i.e., flexibility) and rigidity (e.g., Glass, 2001; Goldberger et al., 2002; Hausdorff et al., 1997, 2001; Wijnants, 2014). Therefore, the first aim of the current study was to examine athletes' temporal structures of performance variation during a sport task in which additional (competition) constraints were not imposed. More specifically, we investigated the temporal structures in series of rowers' ergometer strokes, which were performed at their preferred rhythm. Finding pink noise would provide evidence for the notion that the natural control of rowing strokes emerges from complex systems interactions (cf. Glass, 2001; Van Orden et al., 2003; Wijnants et al., 2009).

Furthermore, research outside the field of sports has shown that temporal structures of variation are closer to pink noise if the motor task is better mastered. In a study on rhythmical aiming, Wijnants et al. (2009) found patterns of pink noise in time series of well-mastered aiming movements, suggesting that a high coordinative functioning between components of the motor system had developed. When aiming movements were less well-mastered the authors found a "whitening" of the structure of performance variation, which suggests less coordination between the system components. Thus, our second aim was to examine whether a relationship exists between the temporal structure of performance variation and the skill-level of rowers. For this aim, we tested whether the temporal structures of variation in ergometer rowing strokes are closer to pink noise for rowers of a better-performing team.

Finally, we chose for rowing on ergometers as a research setup, because this allowed detailed and reliable measurements. In addition, because cyclical (i.e., repetitive) movements lend themselves well for the analysis of temporal structures (e.g., Glass, 2001; Wijnants et al., 2009; Wijnants, Cox, Hasselman, Bosman, \& Van Orden, 2012), this setup was highly suitable for obtaining insights into temporal structures of variation in sport performance. 


\section{Method}

\section{Participants}

Nine competitive male rowers $\left(M_{\text {age }}=19.11, S D=.78\right)$ signed an informed consent form and a medical health form before the start of the study. All participants were members of the same rowing club. They started rowing 7 months earlier, and practiced three times a week in the period of this study, but up to five times a week in the period preceding the study. The participants were part of two different teams, which we distinguished based on the results of early-season competitions for first-year students. Five participants were part of a team ranked between $50 \%$ and $66.67 \%$ nationally (Team A: lower-skilled), and four were part of a team listed among the best $16.67 \%$ nationally (Team B: high-skilled). Note that the terms "lower-skilled" and "high-skilled" are relative to the category of (Dutch) first year's rowers, specifically with regard to the attained levels of performance in the rowing season.

\section{Measures and Procedure}

The research protocol was approved by the Ethical Committee of the Department of Psychology, University of Groningen. For the experiment we used Concept 2 ergometers, Model E (Inc., Morrisville, VT). Between the handle and the chain of the ergometer, a force sensor (MEAS, France) was attached, which was connected to a data acquisition (DAQ) device (NI USB-6009). The DAQ device served to transfer the raw signals to a computer via USB, and these signals were collected in Volts (V) at a frequency of $100 \mathrm{~Hz}$.

Each participant arrived individually for his ergometer session. After the participant did his warm-up activities, we instructed him to perform 550 strokes. This number was chosen in consultation with a coach of the participants' rowing club, who indicated that a rowing session that takes more than 30 min would be a burden for the rowers. A sequence of 550 strokes would last between 20 and 30 min (depending on the participant's stroke frequency), and would provide a sufficient amount of data points to perform reliable analyses (see analysis section). We asked the participant to perform the strokes at his preferred rowing rhythm. Moreover, we set the drag factor on the ergometer to 120 , which corresponds to the resistance set by the participants for their usual workouts.

\section{Analysis}

The obtained time series data (in V) were first low-pass filtered with the Butterworth filter (cut-off frequency $8 \mathrm{~Hz}$ ). The time intervals between the force peaks (maximal force in each stroke) were calculated and formed the unit of analysis. This measure was chosen because the coordination of force exertion is crucial for rowing performance (Hill, 2002; Wing \& Woodburn, 1995).

Detrended Fluctuation Analysis (DFA; Peng et al., 1993), which is particularly suited for nonstationary data and relatively short time series (512 data points in the current study; stroke 18-530), was applied to each participant's peak-to-peak interval series. The result of DFA analysis reveals the relation between window size of data and the mean fluctuation of the windowed data. More specifically, the data series of intervals between force peaks were divided into nonoverlapping 
windows of equal length. The best-fitting trend line was then determined and the average fluctuation (root mean square residual) was calculated. This procedure was repeated for windows of different sizes, ranging from a subset of 4 intervaldata points to 128 interval-data points (i.e., 1/4 times the length of the entire series we analyzed). The relationship between the average fluctuation and window size was plotted on log-log scales (for an illustration, see Figure 2), whereby the slope reflects the DFA exponent. To enhance the interpretation of the results, the DFA exponents were converted into a commonly used fractal dimension (FD) scale based on the conversion formula provided by Wijnants and colleagues (2012a; 2012b):

$$
\mathrm{FD}=.4 \alpha^{2}-1.2 \alpha+2,(2)
$$

where $\alpha$ is the dfa exponent. A resulting FD close to 1.5 reflects white noise, close to 1.1 reflects brown noise, and close to 1.2 reflects pink noise (e.g., Van Orden et al., 2003).

For each rower we determined whether the observed FD fell outside the limits that we may expect in the case of a white noise pattern. Subsequently, we tested whether the temporal structures of the high-skilled rowers (the rowers of Team B) were closer to pink noise than those of the lower-skilled rowers (the rowers of Team A). For this test we used Monte Carlo Permutation, which has high statistical power for smaller sample sizes (e.g., Den Hartigh et al., 2014; Todman \& Dugard, 2001; Van Geert, Steenbeek, \& Kunnen, 2012). To interpret the magnitude of the difference between the teams, Cohen's $d$ (observed difference divided by the pooled $S D$ ) is reported.

\section{Results}

First, to ascertain the validity of our results, for each participant we checked whether the log-log relationship between window size and mean fluctuation approached a straight line in the selected data range, which was the case (for the majority of participants the $r^{2}$ was 1.00 and the lowest $r^{2}$ was .97; see Figure 2 for two representative plots). Then, to determine whether the peak-to-peak interval variations deviated from white noise, we reshuffled the force-peak timeinterval series 100 times for each participant (cf. Hausdorff, Peng, Ladin, Wei, $\&$ Goldberger, 1995). This entails that the mean and standard deviation of the original interval series were kept the same, whereas the sequence of interval-data were randomized. Figure 3 shows that the FD's based on the reshuffled data were characterized by normal curves centered around the value of 1.5, which corresponds to white noise. For each participant the actual FD of the measured interval series fell outside the $95 \%$ confidence limits of the distribution in the direction of pink noise (i.e., a FD of 1.2).

Furthermore, we tested whether the mean FD of high-skilled participants (Team B) was significantly closer to pink noise (i.e., lower) than the FD of the lower-skilled participants (Team A). Figure 4 shows that for each of the high-skilled participants the FD was closer to pink noise than for each of the lower-skilled participants. With the Monte Carlo permutation test we determined the probability that the observed 
difference between the high-skilled rowers and the lower-skilled rowers could be caused by chance alone, by simulating that chance. This was done by repeatedly (10,000 times) redistributing the data to determine the probability of finding the same or a more extreme result. We found that, compared with the lower-skilled participants $(M=1.30, S D=.03)$, the average FD of the high-skilled participants $(M=1.22, S D=.03)$ was significantly lower and closer to pink noise $(p=.003$, $d=3.06)$.

\section{Discussion}

Variation is an essential feature of motor performance, and its structure is assumed to reveal information about the underlying dynamic organization (e.g., Glass, 2001; Goldberger et al., 2002; Van Orden et al., 2003; Wijnants, 2014). By applying nonlinear time series analyses, we found nonrandom variation (i.e., no Gaussian white noise) in rowing-ergometer performance (i.e., intervals between peak forces). Overall, this result is in line with recent findings on pacing of long-distance runners (Hoos et al., 2014) and power output variation of cyclists (Tucker et al., 2006). Considering the converging evidence that the current and previous findings provide, it seems unlikely that sport performance is generated by independently operating component processes that perform specific (motor) functions in relative isolation. In such a case, each rowing stroke would result from a process unrelated to that of the previous stroke, for example when a central pattern generator or motor program commands each new rowing stroke (cf. Goldberger et al., 2002; Wijnants, 2014). ${ }^{1}$

However, contrary to the previous studies in the domain of sports, which reported signatures of brown noise (Hoos et al., 2014; Tucker et al., 2006), we found prominent patterns of pink noise. In fact, none of our participants' force peak-to-peak interval series demonstrated a pattern close to brown noise. Besides the observation that studies conducted in different sports might yield different patterns of variation, the differences between our research outcomes and those of Hoos et al. (2014) and Tucker et al. (2006) are in accordance with our earlier suggestion that additional (competition) constraints may result in a different organization of the motor system. More specifically, these differences support the notion that the competitive situation in the previous studies elicited a relatively rigid organization of the motor system. Indeed, the athletes in the studies of Hoos et al. (2014) and Tucker et al. (2006) probably exerted more conscious control over their performance, which was confirmed by the authors themselves. They stated that athletes in their studies generally followed a "fast-slow-fast" strategy (Hoos et al., 2014) and placed a significant increase in power output near the end of the trial (Tucker et al., 2006). This suggests that athletes made minor adaptations during short periods, nested in relatively large adaptations over the entire performance duration, which is (statistically) typically expressed in a brown noise pattern.

Our second major finding was that high-skilled rowers (i.e., members of a team that was highly ranked nationally) had FDs closer to pink noise than lowerskilled rowers (i.e., members of a team that was ranked slightly below-average). This finding is in accordance with earlier outcomes in the domain of motor control, showing that effective behavior expresses more pink noise than less effective or unhealthy behavior (e.g., Glass, 2001; Goldberger et al., 2002), and that temporal structures of variation show more prominent patterns of pink noise when a task 


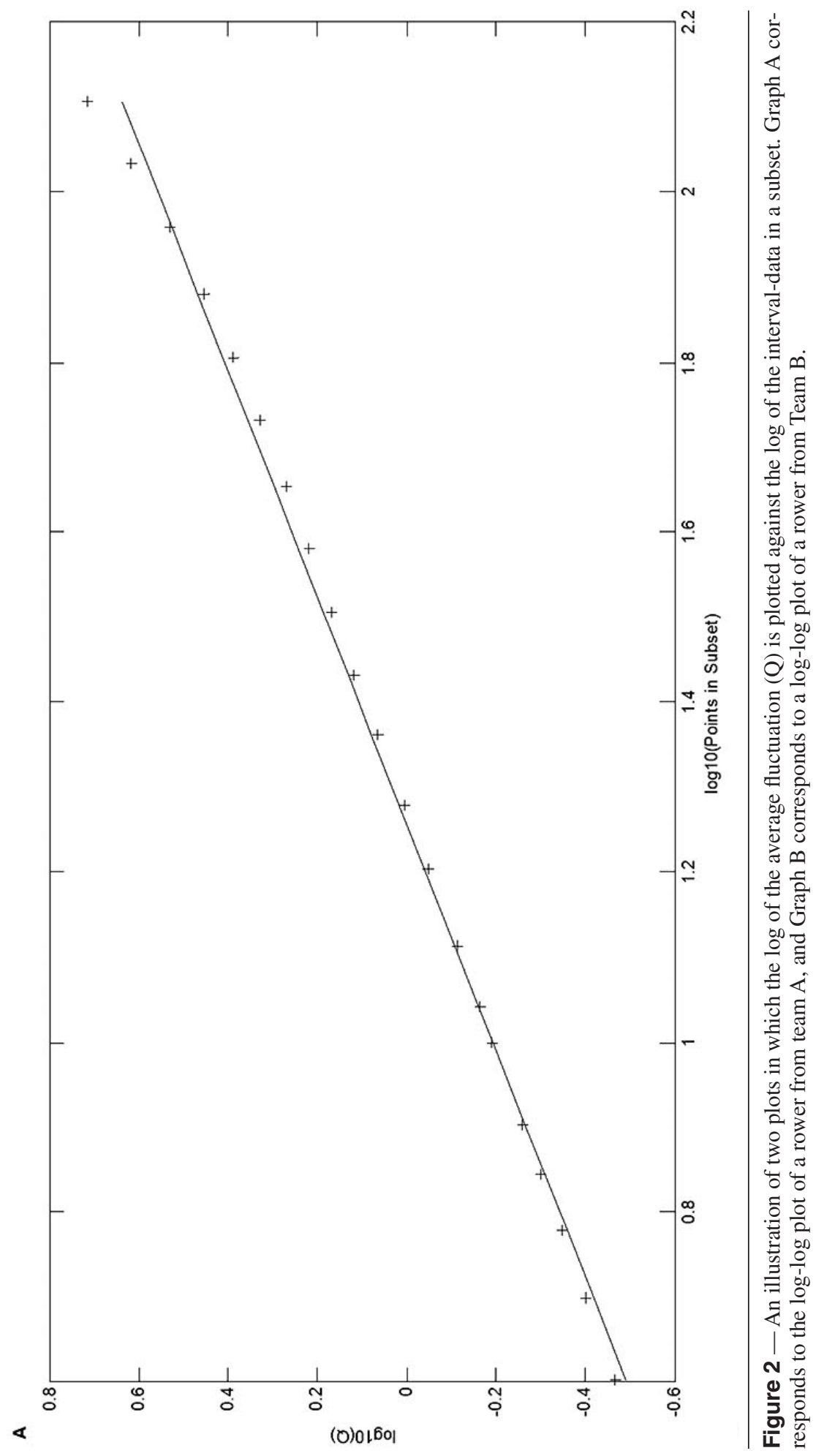




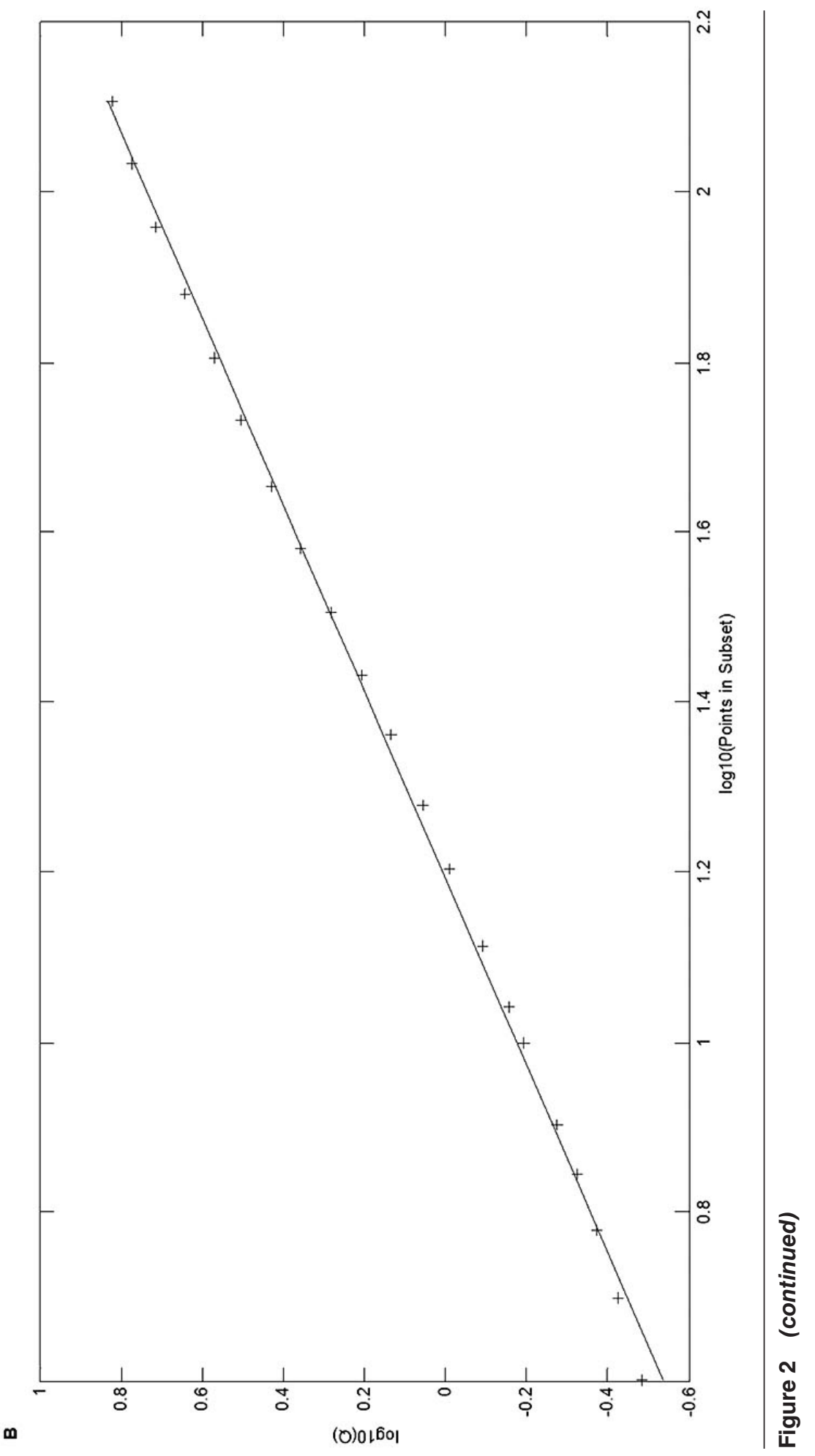

MC Vol. 19, No. 4, 2015 

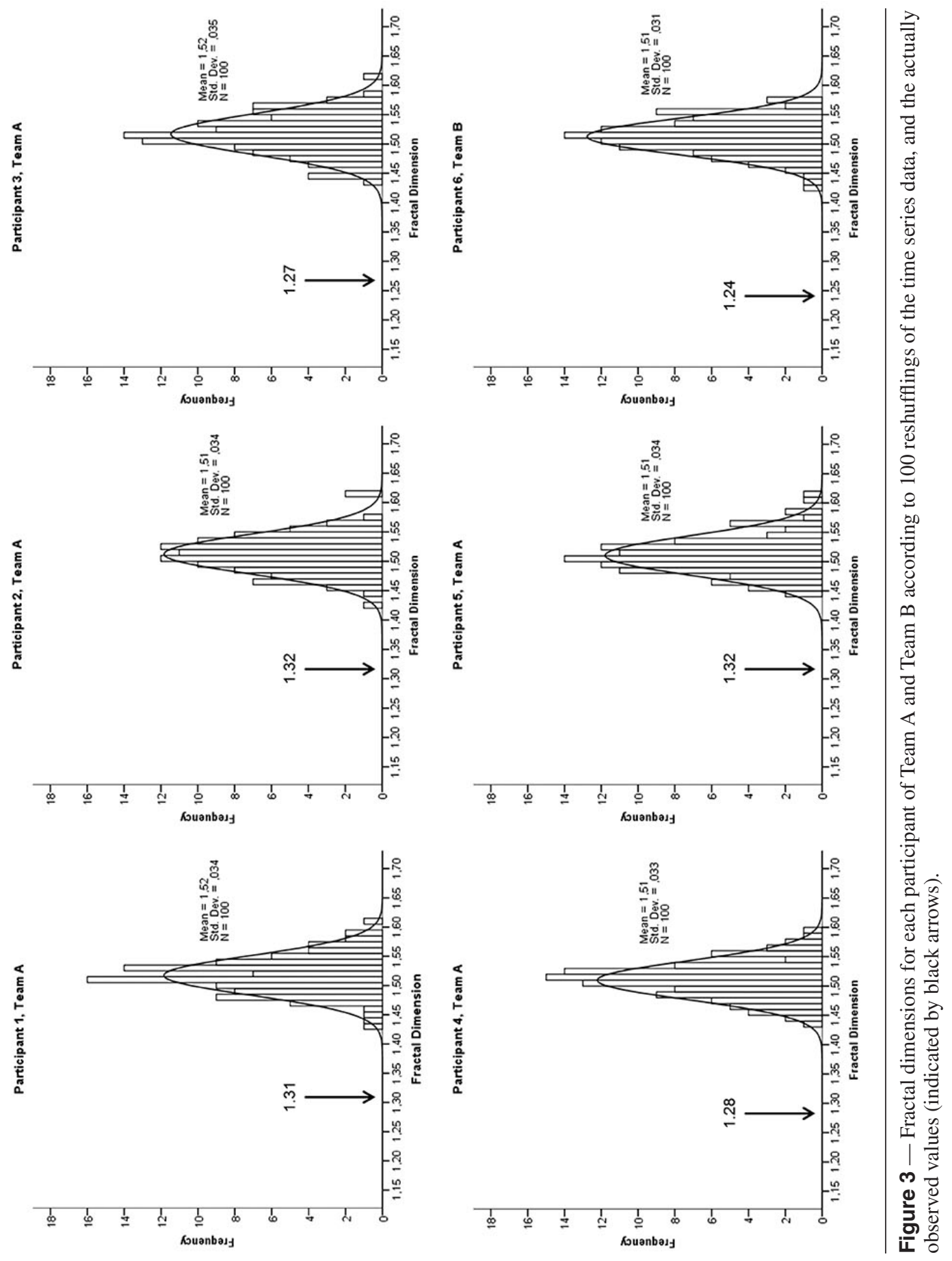

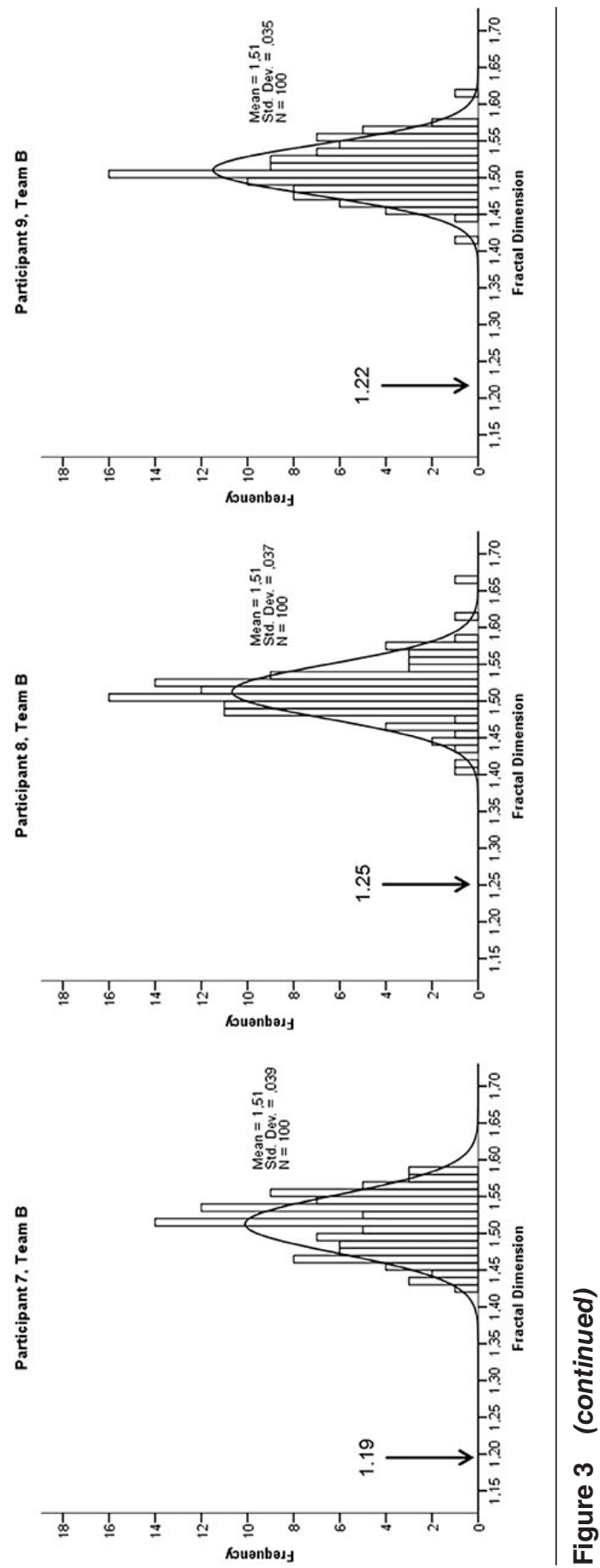

MC Vol. 19, No. 4, 2015 


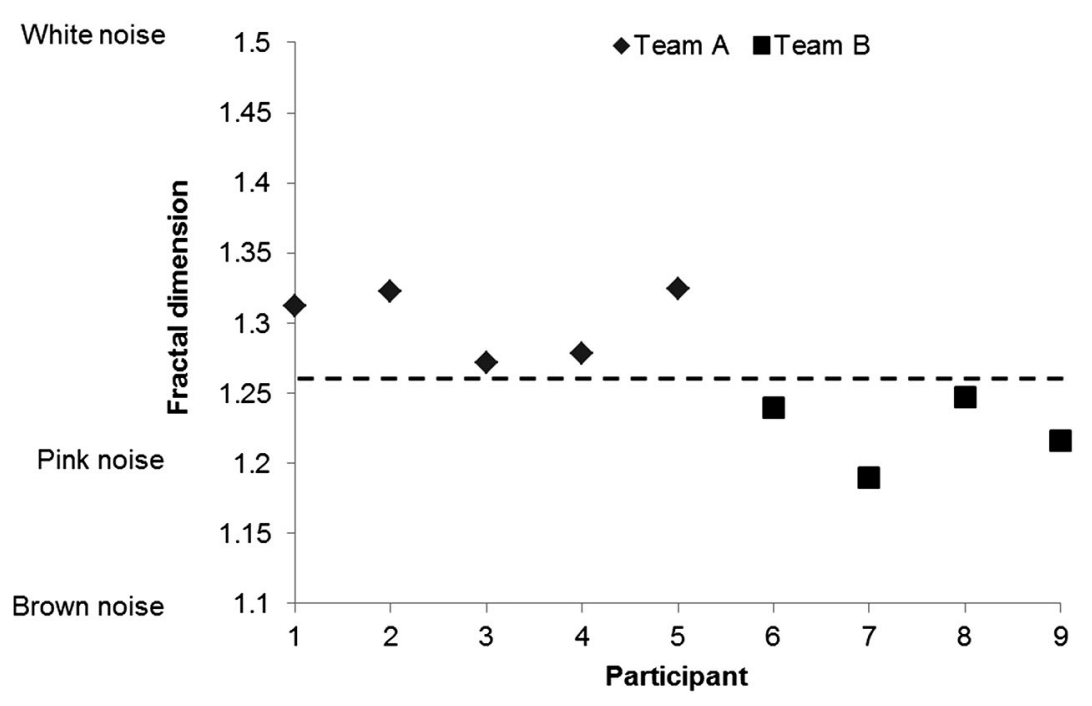

Figure 4 - Fractal dimensions of lower-skilled participants (Team A) and high-skilled participants (Team B). The dashed line separates the rowers of the two teams.

is well-mastered (Wijnants et al., 2009). Therefore, in line with Wijnants et al. (2009) we propose that the coordination among component processes involved in the generation of (relatively unconstrained) rowing strokes is more effective as skill level increases. This is expressed in a more optimal mixture between rigidity and random variation, which may be a key characteristic of elite sport performance (Davids et al., 2003; Phillips et al., 2012; Seifert et al., 2013).

\section{Implications and Limitations}

To date, assessments of sport and motor performance have mainly focused on some potential performance predictor $x$ that may explain a significant portion of variance in performance outcome $y$ (Atkinson \& Nevill, 2001). Such assessments are the result of studies that (a) focus on sample means; (b) do not examine the performance process over time, but take snap-shot measures of the performance; and (c) treat variation as random (i.e., white noise). However, variation during (natural) sport performance can reveal information about the complexity of the system that governs an athlete's behavior, as well as the effectiveness of that behavior, which should not be discarded. Our finding that the temporal structure of variation deviated from white noise for each rower, suggests that single-cause mechanisms or a linear causal chain of component processes are unlikely to account for the resulting rowing ergometer performance. Hence, applying the tools of complex systems science, nonlinear time series in particular, has great potential to advance insights into sport performance processes as they unfold in real-time (Kuznetsov et al., 2014).

One particularly interesting avenue for future research would be to examine how behavioral systems organize themselves under different circumstances. In this study, force-peak interval series of rowers" "natural" stroke performance revealed 
prominent patterns of pink noise. We have suggested that temporal structures of variation in sport performance reveal signatures of brown noise when additional (competition) constraints are imposed. In addition, researchers have proposed that noise patterns may "whiten" when random perturbations are applied to an individual's motor behavior (e.g., Diniz et al., 2011; Wijnants et al., 2009; Wijnants, 2014). Furthermore, we found a clear relation between temporal structures of variation and rowing skill-level. Therefore, in the future, researchers and practitioners should consider information on variation in rowing strokes (and sport performance in general) as a potentially important performance parameter that could be used for monitoring purposes.

However, some limitations should be pointed out with respect to the generalizability of the present findings. Although ergometer rowing is widely used as a means to test rowers, and as a replacement for on-water practice, clear implications of the current study for actual on-water rowing cannot (yet) be provided. The movement pattern of rowing strokes is broadly the same on an ergometer and on water, but the environmental constraints (e.g., the presence of wind and water flow), and thereby the performer-environment interactions, are different (for a discussion of representative experimental designs, see Araújo, Davids, \& Passos, 2007; Pinder, Davids, Renshaw, \& Araújo, 2011). Furthermore, the sample size was rather small, and larger samples including a variety of skill levels could further enrich insights. In the current study we chose to focus on rowers of the same club who did not differ in terms of age and rowing experience, but who had different skill levels as operationalized by their achievements in recent competitions. Despite the small sample size, we found significant and strong results, which provides promising prospects for a complexity perspective on sport and motor performance.

\section{Conclusion}

Our findings clearly indicate that temporal structures of variation in rowers' forcepeak intervals during ergometer rowing are not random, but are close to pink noise. Furthermore, high-skilled rowers expressed even more prominent patterns of pink noise, which is the hallmark of well-coordinated and effective behavior (e.g., Goldberger et al., 2002; Van Orden et al., 2003; Wijnants et al., 2009; Wijnants, 2014). We propose that (skilled) rowers' performance of ergometer strokes naturally emerges from an ongoing dynamic interaction between various component processes across multiple time scales, which is in accordance with the complex systems perspective in sports (Davids et al., 2003, 2014; Seifert et al., 2013). We believe that future applications of the complexity perspective will advance insights in the domain of sport and motor performance.

\section{Notes}

\footnotetext{
${ }^{1}$ Although some researchers have proposed that sources of pink noise can be injected in particular local components such as central pattern generators (Torre \& Wagenmakers, 2009; West \& Scafetta, 2003), researchers have now reached consensus that pink noise does not arise from specific components within the system, but from complex interactions among the system components across different time scales (Delignières \& Marmelat, 2013).
} 


\section{References}

Araújo, D., Davids, K., \& Passos, P. (2007). Ecological validity, representative design, and correspondence between experimental task constraints and behavioral setting: comment on Rogers, Kadar, and Costall (2005). Ecological Psychology, 19, 69-78. doi:10.1080/10407410709336951

Atkinson, G., \& Nevill, A.M. (2001). Selected issues in the design and analysis of sport performance research. Journal of Sports Sciences, 19, 811-827. PubMed doi:10.1080/026404101317015447

Bak, P., Tang, C., \& Wiesenfeld, K. (1987). Self-organized criticality: An explanation of 1/f noise. Physical Review Letters, 59, 381-384. PubMed doi:10.1103/PhysRevLett.59.381

Davids, K., \& Araújo, D. (2010). The concept of 'Organismic Asymmetry'in sport science. Journal of Science and Medicine in Sport, 13(6), 633-640. PubMed doi:10.1016/j. jsams.2010.05.002

Davids, K., Glazier, P., Araújo, D., \& Bartlett, R. (2003). Movement systems as dynamical systems: The functional role of variability and its implications for sports medicine. Sports Medicine (Auckland, N.Z.), 33, 245-260. PubMed doi:10.2165/00007256200333040-00001

Davids, K., Hristoviski, R., Araújo, D., Balaque-Serre, N., Button, C., \& Passos, P. (2014). Complex Systems in Sport. London: Routledge.

Delignières, D., \& Marmelat, V. (2013). Degeneracy and long-range correlations. Chaos: An Interdisciplinary Journal of Nonlinear Science, 23, 043109. PubMed doi:10.1063/1.4825250

Den Hartigh, R.J.R., Van Der Steen, S., De Meij, M., Van Yperen, N.W., Gernigon, C., \& Van Geert, P.L.C. (2014). Characterising expert representations during real time action: A skill theory application to soccer. Journal of Cognitive Psychology, 26, 754-767. doi :10.1080/20445911.2014.955028

Diniz, A., Wijnants, M.L., Torre, K., Barreiros, J., Crato, N., Bosman, A.M., . . Delignières, D. (2011). Contemporary theories of $1 / \mathrm{f}$ noise in motor control. Human Movement Science, 30, 889-905. PubMed doi:10.1016/j.humov.2010.07.006

Dutta, P., \& Horn, P.M. (1981). Low-frequency fluctuations in solids: $1 \mathrm{f}$ noise. Reviews of Modern Physics, 53, 497. doi:10.1103/RevModPhys.53.497

Gilden, D.L. (2001). Cognitive emissions of 1/f noise. Psychological Review, 108, 33-56. PubMed doi:10.1037/0033-295X.108.1.33

Gilden, D.L., Thornton, T., \& Mallon, M.W. (1995). 1/f noise in human cognition. Science, 267, 1837-1839. PubMed doi:10.1126/science.7892611

Glass, L. (2001). Synchronization and rhythmic processes in physiology. Nature, 410, 277-284. PubMed doi:10.1038/35065745

Goldberger, A.L., Amaral, L.A., Hausdorff, J.M., Ivanov, P.C., Peng, C.K., \& Stanley, H.E. (2002). Fractal dynamics in physiology: alterations with disease and aging. Proceedings of the National Academy of Sciences of the United States of America, 99, 2466-2472. PubMed doi:10.1073/pnas.012579499

Hausdorff, J. M., Ashkenazy, Y., Peng, C. K., Ivanov, P. C., Stanley, H. E., \& Goldberger, A. L. (2001). When human walking becomes random walking: fractal analysis and modeling of gait rhythm fluctuations. Physica A: Statistical mechanics and its applications, 302, 138-147. doi: 10.1016/S0378-4371(01)00460-5

Hausdorff, J.M., Peng, C.K., Ladin, Z., Wei, J.Y., \& Goldberger, A.L. (1995). Is walking a random walk? Evidence for long-range correlations in stride interval of human gait. Journal of Applied Physiology, 78, 349-349. PubMed

Hausdorff, J.M., Mitchell, S.L., Firtion, R., Peng, C.K., Cudkowicz, M.E., Wei, J.Y., \& Goldberger, A.L. (1997). Altered fractal dynamics of gait: reduced stride-interval correlations with aging and Huntington's disease. Journal of Applied Physiology, 82, 262-269. PubMed 
Hill, H. (2002). Dynamics of coordination within elite rowing crews: evidence from force pattern analysis. Journal of Sports Sciences, 20, 101-117. PubMed doi:10.1080/026404102317200819

Hoos, O., Boeselt, T., Steiner, M., Hottenrott, K., \& Beneke, R. (2014). Long-range correlations and complex regulation of pacing in long distance road racing. International Journal of Sports Physiology and Performance, 9, 544-553. PubMed doi:10.1123/ IJSPP.2012-0334

Kuznetsov, N., Bonnette, S., \& Riley, M.A. (2014). Nonlinear time series methods for analyzing behavioural sequences. In K. Davids. (Eds.), Complex Systems in Sport. Routledge.

Peng, C.K., Mietus, J., Hausdorff, J.M., Havlin, J.M., Stanley, H.E., \& Goldberger, A.L. (1993). Long-range anticorrelations and non-Gaussian behavior of the heartbeat. Physical Review Letters, 70, 1343. PubMed doi:10.1103/PhysRevLett.70.1343

Phillips, E., Portus, M., Davids, K., \& Renshaw, I. (2012). Performance accuracy and functional variability in elite and developing fast bowlers. Journal of Science and Medicine in Sport, 15, 182-188. PubMed doi:10.1016/j.jsams.2011.07.006

Pinder, R.A., Davids, K.W., Renshaw, I., \& Araújo, D. (2011). Representative learning design and functionality of research and practice in sport. Journal of Sport \& Exercise Psychology, 33, 146-155. PubMed

Press, W.H. (1978). Flicker noises in astronomy and elsewhere. Comments on Astrophysics, 7, 103-119.

Seifert, L., Button, C., \& Davids, K. (2013). Key Properties of Expert Movement Systems in Sport. Sports Medicine (Auckland, N.Z.), 43, 167-178. PubMed doi:10.1007/s40279-012-0011-z

Todman, J.B., \& Dugard, P. (2001). Single-case and Small-n Experimental Designs: A Practical Guide to Randomization Tests. Mahwah, NJ: Lawrence Erlbaum Associates.

Torre, K., \& Wagenmakers, E.J. (2009). Theories and models for 1/f $\beta$ noise in human movement science. Human Movement Science, 28, 297-318. PubMed doi:10.1016/j. humov.2009.01.001

Tucker, R., Bester, A., Lambert, E.V., Noakes, T.D., Vaughan, C.L., \& Gibson, A.S.C. (2006). Non-random fluctuations in power output during self-paced exercise. British Journal of Sports Medicine, 40, 912-917. PubMed doi:10.1136/bjsm.2006.026435

Van Geert, P., Steenbeek, H., \& Kunnen, S. (2012). Monte Carlo techniques: Statistical simulation for developmental data. In S. Kunnen (Ed.), A Dynamical Systems Approach to Adolescent Development. Hove: Psychology Press.

Van Orden, G.C., Holden, J.G., \& Turvey, M.T. (2003). Self-organization of cognitive performance. Journal of Experimental Psychology. General, 132, 331-335. PubMed doi:10.1037/0096-3445.132.3.331

West, B.J., \& Scafetta, N. (2003). Nonlinear dynamical model of human gait. Physical Review E: Statistical, Nonlinear, and Soft Matter Physics, 67, 051917. PubMed doi:10.1103/ PhysRevE.67.051917

Wijnants, M.L. (2014). A review of theoretical perspectives in cognitive science on the presence of scaling in coordinated physiological and cognitive processes. Journal of Nonlinear Dynamics, 14.

Wijnants, M.L., Bosman, A.M., Hasselman, F., Cox, R.F.A., \& Van Orden, G. (2009). 1/f scaling in movement time changes with practice in precision aiming. Nonlinear Dynamics Psychology and Life Sciences, 13, 75-94. PubMed

Wijnants, M.L., Cox, R.F.A., Hasselman, F., Bosman, A.M.T., \& Van Orden, G. (2012a). A trade-off study revealing nested timescales of constraint. Frontiers in Physiology, 3, 116. PubMed doi:10.3389/fphys.2012.00116

Wijnants, M.L., Hasselman, F., Cox, R.F.A., Bosman, A.M.T., \& Van Orden, G. (2012b). An interaction-dominant perspective on reading fluency and dyslexia. Annals of Dyslexia, 62, 100-119. PubMed doi:10.1007/s11881-012-0067-3

Wing, A.M., \& Woodburn, C. (1995). The coordination and consistency of rowers in a racing eight. Journal of Sports Sciences, 13, 187-197. PubMed doi:10.1080/02640419508732227 